\title{
FORMA/AÇÃO DO PROFESSOR DE MATEMÁTICA E SUAS CONCEPÇÕES DE MUNDO E DE CONHECIMENTO
}

\author{
World and knowledge conceptions \\ of Mathematics teachers and their form/action
}

\author{
Roger Miarka ${ }^{1}$ \\ Maria Aparecida Viggiani Bicudo ${ }^{2}$
}

\begin{abstract}
Resumo: Esta pesquisa busca trabalhar com diferentes concepções de mundo e de conhecimento, investigando a articulação entre o sentido que elas possuem para os professores de Matemática e suas concepções de ensino e de Educação. O estudo gira em torno de discussões que ocorreram em um curso de extensão para professores de Matemática. Esse curso tratou de concepções de mundo e de conhecimento, relacionando-as com diferentes regiões do saber, como Matemática, Física, Ecologia e Artes, focando a transição entre a concepção de mundo da Época Moderna para a concepção de mundo que vem se construindo na denominada Época Pós-moderna ou Contemporânea. A meta é compreender o sentido que aquelas concepções têm para os professores e destacar possíveis momentos de metacompreensão sobre a articulação entre essas concepções e sua prática docente. A metodologia utilizada é qualitativa, de uma perspectiva fenomenológica.
\end{abstract}

Palavras-chave: Fenomenologia. Concepções. Conhecimento. Formação de professores. Prática docente.

\begin{abstract}
This research aims to work with different world and knowledge conceptions, inquiring about articulations between the meanings that Mathematics teachers have and their learning and teaching conceptions. This study revolves around discussions that occurred in an extension course for Mathematics teachers. This course addressed different conceptions of world and of knowledge, and their association with different fields such as Mathematics, Physics, Ecology and Arts, focusing on the transition between the Modern Era world conception and the world conception that has been evolving in the so-called Post-Modern Era. The goal is to understand the meanings that teachers have about those conceptions, highlighting possible moments of meta-understanding regarding the articulation between these conceptions and their practice. A qualitative research methodology was employed for the study from a phenomenological perspective.
\end{abstract}

Keywords: Phenomenology. Conceptions. Knowledge. Teachers' education. Teacher practice.

${ }^{1}$ Licenciatura e Bacharelado em Matemática, doutorando em Educação Matemática, Universidade Estadual Paulista (Unesp), campus de Rio Claro. Rio Claro, SP, Brasil. <romiarka@gmail.com>

${ }^{2}$ Licenciatura e Bacharelado em Pedagogia, doutora em Educação. Docente, Departamento de Matemática, Unesp, campus de Rio Claro. Rio Claro, SP, Brasil. <mariabicudo@gmail.com>

${ }^{1}$ Unesp - Departamento de Matemática

Av. $24 \mathrm{~A}, 1515$

Bela Vista - Rio Claro, SP

$13.506-700$

557

Ciência \&̊ Educação, v. 16, n. 3, p. 557-565, 2010 
Miarka, R.; Bicudo, M. A. V.

\section{Introdução}

Este artigo destina-se a explicitar as articulações compreendidas em uma pesquisa efetuada com professores de Matemática durante um curso de formação continuada ocorrido no Brasil, que buscou trabalhar com diferentes concepções de mundo e de conhecimento, investigando a articulação entre o sentido que elas fazem para os professores de Matemática e suas concepções de ensino e de Educação (MIARKA, 2008). Esse curso, com duração de 32h, foi denominado "Concepções de mundo e de conhecimento: a virada".

A meta da investigação foi compreender o sentido que concepções de mundo, conhecimento, Ciência, Matemática e Educação e suas articulações fazem para os professores, e como a presença dessas concepções se presentificam em sua prática docente. Para tanto, optou-se por trabalhar segundo uma abordagem fenomenológica, privilegiando os discursos dos participantes tais como eram proferidos no contexto das atividades de ensino e de aprendizagem, promovidas durante a realização do curso mencionado. Não foi estruturado um instrumento prévio contendo os indicadores dos dados supostamente significativos, de acordo com as concepções dos pesquisadores, mas foram consideradas as próprias descrições explicitadas pelos professores participantes do curso. Essas descrições constituíram-se de textos obtidos mediante entrevistas não diretivas, de relatos escritos das discussões ocorridas e de uma síntese escrita realizada após o encerramento do curso.

\section{O curso}

No Brasil, a formação do professor de Matemática ocorre no Ensino Superior, no grau que se denomina graduação, geralmente com duração de oito semestres após o Ensino Médio, cujos currículos versam sobre: Matemática, com foco nas disciplinas de Álgebra, Geometria e Análise, e Educação, como Psicologia da Aprendizagem, Estrutura do Sistema Escolar, Prática de Ensino de Matemática e algumas disciplinas de caráter mais voltado à aplicação. Nos dois ou quatro últimos semestres, há atividades de estágio supervisionado. Os cursos de formação continuada dirigem-se para professores em serviço, ou seja, para aqueles que estão trabalhando em salas de aula com ensino de Matemática. Eles são comuns no Brasil, ocorrendo em diferentes modalidades em termos de duração e de conteúdo, envolvendo cursos de caráter mais pragmático, teórico ou ambos.

O curso 'Concepções de mundo e de conhecimento: a virada' tratou de concepções de mundo e de conhecimento, relacionando-as com diferentes regiões do saber, como Matemática, Física, Ecologia e Artes, focando a transição entre a concepção de mundo da Época Moderna e a concepção de mundo que vem se construindo na denominada Época Pós-moderna ou Contemporânea. Ele foi organizado de modo a ser ministrado em 16 encontros temáticos, com duração de duas horas, indicados na Tabela $1 \mathrm{com}$ os respectivos textos e filmes fomentadores de discussões. 
Tabela 1. Temáticas abordadas no curso.

\begin{tabular}{cl}
\hline Encontro & \multicolumn{1}{c}{ Tema } \\
\hline 1 & $\begin{array}{l}\text { Realidade compreendida pela soma de suas partes e realidade compreendida pela totalidade (ILHA, } \\
\text { 1989). }\end{array}$ \\
2 & $\begin{array}{l}\text { Concepção galiláica: rigor, neutralidade e objetividade matemática para descrever fenômenos da } \\
\text { natureza/ Estruturação Cartesiana de mundo e de conhecimento: relação parte/todo, todo entendido } \\
\text { como somatória das partes, e conhecimento visto como produzido mediante separação de sujeito e } \\
\text { objeto (GALILEU, 1999; DESCARTES, 1989). }\end{array}$ \\
& Concepções de Tempo e Espaço: abordagem cartesiana e abordagem de Poincaré (POINCARÉ, \\
& 1984). \\
4 & Modelo Cartesiano é questionado (OMNÉS, 1996). \\
5 & A máquina de Newton e a Teoria da Relatividade (ANASTÁCIO, 1999; HEISENBERG, 1999). \\
7 & Concepções de espaço-tempo: abordagem advinda com a Teoria da Relatividade (HEISENBERG, \\
8 & 1999; BICUDO, 2003a). \\
9 & A questão da falibilidade da lógica (LAKATOS, 1978). \\
10 & Concepção de verdade: exatidão e objetividade (FOUCAULT, 1999). \\
11 & Concepção de verdade: verdade como sentido (PIETTRE, 2005). \\
12 & Relações entre Matemática, Física e Artes (OSTROWER, 1983). \\
13 & Entrelaçamento do mundo: consciência da existência do todo (O PONTO..., 1990). \\
14 & Entrelaçamento do mundo: consciência da existência do todo (CAPRA, 1982). \\
15 & A questão da Complexidade e sugestão de ensino (MORIN..., 2006). \\
16 & A questão da Complexidade e sugestão de ensino (MORIN, 2002). \\
\hline
\end{tabular}

Cada encontro teve como suporte didático recortes de textos de autores significativos para o tema tratado, indicados na tabela acima. No Encontro 02, por exemplo, os recortes trabalhados foram extraídos dos textos O Ensaiador (GALILEU, 1999) e Discurso do método (DESCARTES, 1989). Esses textos eram tomados como disparadores de discussões entre os professores presentes no curso.

A organização dos temas do curso seguiu uma lógica transdisciplinar, partindo do modo como as concepções abordadas se mostravam, e não por meio das disciplinas que tradicionalmente, na História da Ciência, são responsáveis pelo desenvolvimento dessas concepções. Assumimos essa organização pautados na concepção de transdisciplinaridade de Bicudo (2008, p. 148):

A transdisciplinaridade leva consigo o sentido de ir além das disciplinas, mas ir de certo modo, caracterizado pelo sufixo dade. Esse modo é indicado pelas concepções de mundo e de conhecimento e, também pelos valores, que apontam a ética assumida, em uma atitude que persegue a transformação. Transformação do quê? Dos conteúdos disciplinares, não mais olhados nos limites da disciplina, mas abrindo-os a outras possibilidades de compreensão de um tema sob análise investigadora. Essas possibilidades vão sendo descortinadas no próprio processo de investigação, sempre rigoroso, no sentido de haver cuidado com as articulações efetuadas, com as concepções assumidas, com os 
Miarka, R.; Bicudo, M. A. V.

procedimentos escolhidos, na medida em que a linguagem, a história, o contexto sócio-político-econômico são considerados como basilares, assim como basilar é a perspectiva de onde o investigador fala e para onde se dirige.

Durante o curso, foi assumida a atitude fenomenológica na relação com os professores, explicitada pela abertura ao outro, ouvindo-os em suas manifestações e colocando-nos como participantes do debate e das atividades efetuadas. A atitude fenomenológica foi assumida, pois busca trabalhar com o real vivido. O pensar fenomenológico não aceita o que está posto sem questionamentos, sem críticas. Isso significa que, no desenrolar das atividades de ensino e de aprendizagem efetuadas, a postura crítica se fazia presente, tanto com relação aos conteúdos lidos como com relação aos modos pelos quais as pessoas explicitavam suas compreensões e se dirigiam umas às outras, constituindo uma realidade intersubjetiva em que a relação dialógica estava presente. Essa relação serviu como suporte para explicitar o significado compreendido para que pudesse ocorrer a articulação buscada, evidenciada no que se mostrava, e não no discurso de outrem (BICUDO, 1999).

\section{Os dados}

O curso transcorreu mediante solicitações de: leituras atentas dos textos, exposições do compreendido concomitantes ao diálogo científico, por se tratar da exposição das dúvidas, observações, concordâncias e discordâncias referentes ao interpretado e discutido; elaboração de textos escritos concernentes às sínteses compreensivas de cada tema investigado; e elaboração de uma síntese final a ser entregue um mês após o término do curso.

Foram considerados dados para a análise: as sínteses individuais elaboradas após cada encontro; o áudio referente à discussão ocorrida no último encontro do curso, cujo objetivo era estabelecer articulações entre os temas tratados ao longo de todo o curso e como cada professor se via em termos de suas concepções; o áudio referente a entrevistas individuais efetuadas ao final do curso, cuja pergunta orientadora era "que sentido o curso fez para você??; e um ensaio final efetuado individualmente e entregue um mês após o término do curso.

\section{A análise}

Para a análise dos dados, priorizamos o "Ensaio individual final", que se constituía por texto escrito pelos alunos visando que expusessem sua compreensão refletida sobre o vivenciado, a qual foi sendo construída subjetiva e intersubjetivamente ao longo do curso.

Apesar de não analisarmos profundamente os outros grupos de dados coletados, deles lançamos mão para compreender melhor o que se mostrava nos ensaios finais.

É importante esclarecer que, no movimento de análise efetuada fenomenologicamente, o pesquisador mantém-se presente, atento. Sabe que não é possível desfazer-se de suas crenças prévias e suas próprias concepções, porém, coloca-as sob atenção, de tal maneira que possa transcender sua esfera de subjetividade, doando-se à pesquisa, abrindo-se ao investiga- 
do. Quando isso ocorre, o movimento da epoché, de colocar em evidência os aspectos significativos em relação ao objeto da pesquisa, está se dando, e reduções sucessivas vão sendo elaboradas, constituindo-se, então, a investigação fenomenológica. Esse movimento é essencial, visto que, pela redução, os atos da consciência expõem-se, ou seja, toma-se ciência deles de modo que, pela reflexão - um de seus componentes - são explicitadas as raízes cognitivas das próprias afirmações (BICUDO, 2000).

Como primeiro momento da análise, foram efetuadas diversas leituras dos textos obtidos, focalizando a explicitação dos significados e sentidos que concepções sobre mundo e conhecimento fazem para os professores. Ou seja, buscamos ficar atentos aos modos pelos quais esses sentidos e significados eram expressos, deixando-nos conduzir pelo movimento de meta-compreensão e pela relação concepção/meta-compreensão/prática docente. Nesse movimento de interpretação, foram destacados trechos que nos diziam do fenômeno investigado, que foram denominados de Unidades de Significado (US).

Por motivos organizacionais, as US foram codificadas usando-se dois campos. No primeiro campo, utilizamos uma letra representativa para cada professor participante do grupo, e, no segundo campo, indicamos a ordem em que a US aparece dentro do texto do qual foi extraída. de Ana ${ }^{3}$.

Segue um exemplo: a US A4, que codifica o trecho referente à $4^{a}$ US do ensaio final

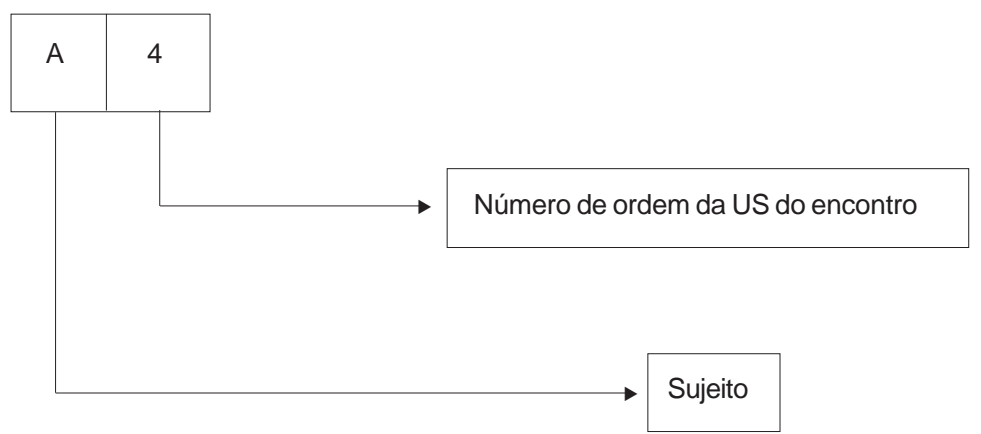

Essas US foram analisadas hermeneuticamente, de modo que o nelas dito foi se abrindo à compreensão dos pesquisadores mediante o recurso de estabelecer um movimento dialético entre: o dito, o texto em sua totalidade, e possíveis significados carregados históricoculturalmente pela tradição linguística. A compreensão dos pesquisadores obtida com esse movimento a respeito das US foi explicitada em uma linguagem apropriada aos pesquisadores e à comunidade científica da qual fazem parte.

\footnotetext{
${ }^{3}$ Todas as iniciais utilizadas no primeiro campo se referem a pseudônimos escolhidos pelos próprios participantes do curso.
} 
Miarka, R.; Bicudo, M. A. V.

Explicitadas essas interpretações, atentamo-nos às articulações que se mostravam entre essas US, de modo a buscar convergências de significado. Após duas reduções, atentos aos invariantes abrangentes, obtivemos cinco categorias abertas, que foram nomeadas e articuladas em um discurso inteligível.

De acordo com Martins e Bicudo (1989), essas categorias são chamadas de abertas em contraposição às categorias como concebidas aristotelicamente. Para a Fenomenologia, elas são grandes regiões, não apriorísticas, de generalizações.

Essas grandes convergências foram, então, expostas em uma configuração de rede, a qual chamamos de Rede de Significados, interpretando núcleos de convergência dos significados. Assim procedendo, foram enfocados os significados que as concepções sobre mundo e conhecimento, abordados no curso, trazem para os professores de Matemática, o modo pelo qual realizam o movimento de metacompreensão e como percebem a relação concepção/metacompreensão/prática docente.

Essas categorias de convergência foram interpretadas, visando transcender às manifestações individuais, e um trabalho de teorização foi realizado, sintetizando as interpretações das falas dos depoentes, a literatura estudada e as concepções do pesquisador, expondo possibilidades de forma/ação continuada do professor de Matemática.

Esse termo 'forma/ação' foi cunhado para enfatizar o significado de forma, como formato ou aparição de algo que toma forma por meio de um ato atualizador, o qual lhe serve como conteúdo e força que impele à forma apresentada (BICUDO, 2003b). No caso da formação do professor de matemática, essa forma/ação ocorre no próprio ato de efetuar a educação informadora e formadora. Com essa concepção fenomenológica de forma/ação, o foco passa a ser o movimento constante de pensar e repensar a ação, em um movimento de açãoreflexão-ação-reflexão do professor, por entendermos que o profissional nunca está formado, mas sempre em processo de forma/ação.

\section{As categorias de convergências}

Interpretando as reduções apresentadas, mediante um trabalho de reunião de significados, ou seja, de deixar o logos mostrar-se no movimento do próprio pensar, indicamos que as ideias presentes nas US convergiram para cinco categorias. Estas categorias foram nomeadas de: "Do significado de concepções de mundo", "Do significado de concepções de educação", "Da articulação entre concepções", "Da percepção da própria concepção" e "Da mudança de concepções". Apresentaremos, a seguir, uma síntese das discussões que caracterizam essas categorias, assim como algumas US explicitadoras.

A categoria "Do significado de concepções de mundo" mostra modos como concepções de mundo e de conhecimento estão presentes na vida dos professores e no mundo que os cerca. Desponta-se um pensar sobre o tema, no qual articulações são explicitadas. $\mathrm{O}$ Outro e o mundo são postos em foco, em busca de compreensões de modos de articulações que se evidenciam: 
'[...] por deixarem de englobar a subjetividade presente no universo, [os modelos galiláico e cartesiano] acabam por apresentar certas limitacões e deixam de responder a algumas questões" (M5). "Não consegui mudar o meu modo de agir e a minha forma de pensar, mas agora sei que há uma maneira menos objetiva, exata e talvez até menos [im]parcial de pensarmos" (D2).

"Do significado de concepções de educação" nos fala de significados atribuídos para aspectos relacionados à educação. Por vezes, esse significado é posto como núcleos objetivos, constituídos no movimento subjetividade/ intersubjetividade/objetividade, e mantidos no modo da tradição por meio da linguagem. Outras vezes, há a explicitação de núcleos de sentido do depoente, constituídos, por sua vez, na articulação do significado atribuído com as crenças e suas experiências vividas.

"A educação, da forma que se encontra atualmente, mostra os conbecimentos aos alunos de forma fragmentada, esquecendo de lhes ensinar de que forma aquelas informações podem ser religadas e assumir algum sentido." (M17)

A categoria "Da articulação entre concepções" nos fala dessa articulação entre concepções de mundo, de conhecimento e de Educação:

"[...] [a educação está sendo realizada através de um somatório de partes,] característica do modelo cartesiano." (A5)

"De nada vale conhecer inumeras teorias da Física, saber aplicar outras tantas fórmulas matemáticas e decorar infinitas datas na aula de bistória se fora do âmbito escolar todas estas informações não tiverem aplicabilidade, se o discente não puder ver uma ligação entre elas e sua presença em todo o mundo.” (M18)

Em "Da percepção da própria concepção", são interpretadas as aberturas que os participantes da discussão efetuaram em relação à sua própria concepção. $\mathrm{O}$ voltar-se às nossas concepções, colocando-as em destaque como se mostram a nós mesmos, ao outro, no mundo em que vivemos e no-mundo-com-os-outros, indica o movimento de reflexão, de autoconhecimento e de compreensão refletida das concepções assumidas ou que estão a caminho de serem assumidas:

"Estamos acostumados com o modelo cartesiano, ou seja, com um mundo fixo, objetivo" (D3).

"Da mudança de concepções" trata das mudanças antevistas pelos participantes do curso. Nela, eles falam de suas próprias concepções, sobre o voltar-se a elas, sobre o projeto de mudança e da mudança-com-o-outro-no-mundo.

"Admitindo [-se] que algum dia isto acontecerá as pessoas passariam a compreender como não se pode buscar uma única causa para algum problema, como cada 
Miarka, R.; Bicudo, M. A. V.

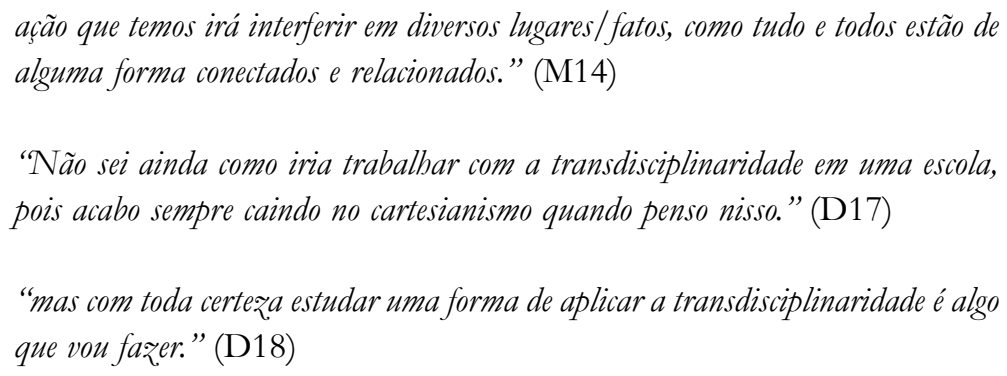

Compreendemos, nesse movimento em que a formação de professores de Matemática foi se dando, que não há primazia de uma concepção de ciência e de conhecimento, como sendo a melhor ou a correta, mas há articulação entre diferentes concepções que se alternam em importância conforme o assunto tratado e o contexto vivido. Além disso, os professores nem sempre se dão conta das maneiras pelas quais essas concepções se presentificam nas suas próprias ações. Esse ato de 'dar-se conta de', que se espera esteja presente na postura profissional do professor, exige um trabalho rigoroso e intencionado de metacompreensão, ou seja, de um pensar sobre o pensado, de compreender os modos como o compreendido se manifesta nas próprias ações e modos de agir.

\section{Referências}

ANASTACIO, M. Q. A. Três ensaios numa articulação sobre a racionalidade, o corpo e a educação na Matemática. 1999. 146f. Tese (Doutorado em Educação) - Faculdade de Educação, Universidade Estadual de Campinas, Campinas, 1999.

BICUDO, M. A. V. A pesquisa interdisciplinar: uma possibilidade de construção do trabalho científico/acadêmico. Revista Educação Matemática, São Paulo, v. 10, n. 1, p. 137-150, 2008.

Tempo, tempo vivido e história. Bauru: EDUSC, 2003 a.

Formação do professor: um olhar fenomenológico. In: (Org.). Formação

de professores? Da incerteza à compreensão. Bauru: EDUSC, 2003b. p. 7-46.

Fenomenologia: confrontos e avanços. São Paulo: Cortez, 2000.

Contribuição da Fenomenologia para a educação. In: BICUDO, M. A. V.;

CAPPELLETTI, I. F. (Orgs). Fenomenologia: uma visão abrangente da educação. São Paulo: Olho D’água, 1999. p. 11-51.

CAPRA, F. O ponto de mutação. São Paulo: Cultrix, 1982.

D’AMBROSIO, U. Transdisciplinaridade. São Paulo: Palas Athena, 1997. 
Forma/ação do professor de Matemática ...

DESCARTES, R. Discurso do método. Trad. Elza Moreira Marcelina. Brasília: Editora UnB, 1989.

FOUCAULT, M. A verdade e as formas jurídicas. Rio de Janeiro: Nau, 1999.

GALILEU, G. O ensaiador. São Paulo: Nova Cultural, 1999. (Os Pensadores).

HEISENBERG, W. Física e filosofia. 4. ed. Brasília: Ed. da UnB, 1999.

ILHA das flores. Direção: Jorge Furtado. Porto Alegre: Casa de Cinema Poá, 1989. 1 DVD (13 $\mathrm{min})$.

LAKATOS, I. História da ciência e suas reconstruções racionais e outros ensaios. Lisboa: Edições 70, 1978.

MARTINS, J.; BICUDO, M. A. V. A pesquisa qualitativa em Psicologia: fundamentos e recursos básicos. São Paulo: Moraes, 1989.

MIARKA, R. Concepções de mundo de professores de matemática e seus horizontes antevistos. 2008. 162f. Dissertação (Mestrado em Educação Matemática) - Universidade Estadual Paulista, Rio Claro, 2008.

MORIN, E. Educação na era planetária: conferência. In: FÓRUM DE DEBATES UNIVERSO DO CONHECIMENTO, 2005, São Paulo. Conferência... São Paulo: Cultura Marcas, 2006. 1 DVD (120 min). 2002.

Educação e complexidade: os sete saberes e outros ensaios. São Paulo: Cortez,

OMNÉS, R. Filosofia da ciência contemporânea. São Paulo: Ed. Unesp, 1996.

OSTROWER, F. Universos da arte. 16. ed. Rio de Janeiro: Campus, 1983.

PIETTRE, B. Vérité et sens. Revista Pesquisa Qualitativa, São Paulo, v. 1, n. 1, p. 27-72, 2005.

POINCARÉ, H. O valor da ciência. Rio de janeiro: Contraponto, 1984.

O PONTO de mutação. Direção: Bernt Capra. Produção de roteiro: Frijof Capra. [S. 1.]:

Ocean Films, 1990.1 videocassete (106 min), VHS, son., color.

Artigo recebido em julho de 2010 e aceito em novembro de 2010. 